\title{
BMJ open Tobacco consumption and secondhand smoke exposure in vehicles: a cross-sectional study
}

\author{
Ariadna Curto, ${ }^{1,2}$ Jose M Martínez-Sánchez,, ${ }^{1,3,4}$ Esteve Fernández ${ }^{1,3,4}$
}

To cite: Curto A,

Martínez-Sánchez JM,

E Fernández. Tobacco consumption and

secondhand smoke exposure in vehicles: a cross-sectional study. BMJ Open 2011;1: e000418. doi:10.1136/ bmjopen-2011-000418

- Prepublication history for this paper is available online. To view these files please visit the journal online (http:// bmjopen.bmj.com).

Received 27 September 2011 Accepted 31 October 2011

This final article is available for use under the terms of the Creative Commons Attribution Non-Commercial 2.0 Licence; see http://bmjopen.bmj.com

\footnotetext{
${ }^{1}$ Tobacco Control Unit, Cancer Control and Prevention Programme, Institut Català d'Oncologia-ICO, L'Hospitalet de Llobregat, Barcelona, Spain

${ }^{2}$ Department of Experimental and Health Sciences, Universitat Pompeu Fabra, Barcelona, Spain

${ }^{3}$ Cancer Control and

Prevention Group, Institut d'Investigació Biomèdica de Bellvitge-IDIBELL,

L'Hospitalet de Llobregat, Barcelona, Spain

${ }^{4}$ Department of Clinical Sciences, Universitat de Barcelona, Campus de Bellvitge, L'Hospitalet del Llobregat, Barcelona, Spain

Correspondence to Dr Jose M Martínez-Sánchez; jmmartinez@iconcologia.net
}

\begin{abstract}
Objectives: To estimate the prevalence of tobacco consumption and secondhand smoke (SHS) exposure in private cars, commercial vehicles and taxis in the city of Barcelona in Spain.
\end{abstract}

Design setting and participants: We carried out an observational cross-sectional study in 2011. We selected a systematic sample of 2442 private cars, commercial vehicles and taxis on 40 public roads regulated by traffic lights in all 10 districts of Barcelona. We calculated the prevalence rates and $95 \% \mathrm{Cls}$ of smoking and SHS exposure in cars, and the corresponding ORs adjusting for the potential confounding variables.

Results: The prevalence of tobacco consumption was $5.5 \%(95 \% \mathrm{Cl} 4.6 \%$ to $6.4 \%)$ and was greater for commercial vehicles (9.8\%; $95 \% \mathrm{Cl} 7.1 \%$ to $12.5 \%$ ). The prevalence of SHS exposure was $5.2 \%(95 \% \mathrm{Cl}$ $3.8 \%$ to $6.6 \%)$ and $2.2 \%(95 \% \mathrm{Cl} 0.5 \%$ to $3.9 \%)$ of passengers under 14 years of age were exposed to SHS in vehicles.

Conclusions: This study highlights the need to promote public health measures aimed at reducing tobacco consumption in vehicles, especially in the presence of children, as well as enforcement of the current Spanish law against smoking in commercial vehicles and taxis.

\section{INTRODUCTION}

Secondhand smoke (SHS) contains a complex mixture of pollutants that includes toxic and irritant compounds, as well as carcinogens. ${ }^{12}$ SHS has been classified by the International Agency for Research on Cancer (IARC) as a type I carcinogen in humans. ${ }^{2}$ In 2004 it was estimated that $1 \%$ of global mortality (603000 deaths) was attributable to SHS exposure. ${ }^{3}$ Specifically, in Spain, it was estimated that between 1228 and 3237 deaths from lung cancer and myocardial infarction were attributable to SHS exposure in $2002 .^{4}$

Although there is a dose-response effect and no level of SHS exposure can be

\section{ARTICLE SUMMARY}

Article focus

- Tobacco consumption and secondhand smoke (SHS) exposure in vehicles should be targeted because of the high concentrations of SHS due to the confined environment.

- Tobacco consumption while driving can also increase the risk of traffic accidents due to driver distraction.

- Few studies have used direct observation to examine the consumption of tobacco and SHS exposure in vehicles.

Key messages

- Reducing smoking in vehicles in the presence of children must be prioritised.

- Smoking laws should be enforced in commercial vehicles and taxis.

- Smoking in vehicles should be recognised by legislation as a distraction.

Strengths and limitations of this study

- The main limitation of this study is the inherent observer bias, especially as regards variables such as age, where physical appearance can result in misclassification by the observer.

- Obtaining a truly random and representative sample of vehicles in circulation in a city is difficult.

- This observational study avoids the information bias generated by the use of self-reported questionnaires.

- A pilot study found that direct observational studies are useful for monitoring smoking by motor vehicle drivers.

considered safe, ${ }^{5}$ the intensity of the exposure depends on the length of exposure and the concentration of SHS in the air. Therefore, because they are confined environments, tobacco consumption and SHS exposure in vehicles deserves special attention as SHS concentrations can be much higher than in the home, workplace or leisure settings such as discos and bars. ${ }^{6}{ }^{7}$ Moreover, concentrations of $\mathrm{PM}_{2.5}$ (particulate matter with a diameter below $2.5 \mu \mathrm{m}$ ) in 
vehicles where people are smoking ${ }^{6-10}$ can exceed the limits recommended by the US Environmental Protection Agency. ${ }^{11}$

Few studies have examined the consumption of tobacco and SHS exposure in vehicles through direct observation $^{12}{ }^{13}$; to our knowledge, only one crosssectional study using questionnaires has been carried out in Spain. ${ }^{14}$ The objective of this study was to estimate the prevalence of tobacco consumption and SHS exposure in private cars, commercial vehicles and taxis in the city of Barcelona.

\section{METHODS}

\section{Sampling, sample size and site selection}

A cross-sectional study was conducted using direct observation of the occupants of private cars, commercial vehicles and taxis in the city of Barcelona. The fieldwork was carried out in April and May 2011. For each of the 10 districts of Barcelona, we randomly selected two public roads of the 15 with the greatest traffic flow rates and two public roads of the five with the greatest density of nurseries and primary and secondary schools to ensure the presence of children in vehicles. We consulted the 2011 'Araña de Tráfico' of the Mobility Services Division of Barcelona City Council when choosing the public roads. ${ }^{15}$ We selected a total of 40 public roads (four per district, two with greater traffic flow rates and two with greater school density). For each of the public roads, a traffic light was selected as the observation point where a trained observer directly observed the vehicles and recorded the variables of interest on a specially designed data collection sheet.

The theoretical sample size was 2401 vehicles assuming an expected prevalence of $50 \%$ with a $95 \%$ confidence interval (CI) and a precision of $2 \%$. Two previous studies in Italy and Spain had prevalence rates of $10 \%$ and $20 \%$, respectively. ${ }^{12}{ }^{14}$ However, we assumed a $50 \%$ prevalence to maximise statistical power in order to stratify the results by type of vehicle. The final sample size was 2442 vehicles. The number of observations was distributed in proportion to the rates of traffic flow on each public road. The observations were carried out when traffic lights were set at red for vehicles. We systematically selected the first two vehicles in the lane adjacent to the observer. We excluded adjacent lanes which were restricted to buses, taxis and bicycles. The study included any private car, commercial vehicle (tourist related, adapted mixed vehicles and vans carrying a company logo or slogan) or taxi. We excluded buses, coaches, trucks, motorcycles, bicycles and other public service vehicles (ambulances, police cars, driving school cars, etc). We also excluded cars with tinted windows that did not allow the occupants to be observed. When a vehicles did not meet the inclusion criteria, we observed the next vehicle in line. The observations were carried out continuously for an average duration of $1 \mathrm{~h}$ from 8:00 to 11:00 $\mathrm{h}$ and from 17:00 to 19:00 h, Monday through Friday.

\section{Study variables}

We defined the variables for drivers, passengers and vehicles. The driver variables studied were: tobacco consumption (yes, no), approximate age (18-34, $35-64$, and $\geq 65$ years) and sex (male, female). Passenger variables were: total number of passengers, number of passengers who smoked and number of passengers under 14 years of age. Vehicle variables were: type of vehicle (private car, commercial vehicle, taxi), number of open windows, and whether the driver's window was open (yes, no). We also collected contextual variables (day of the week, district, time, weather and number of lanes on the road).

The two main variables, tobacco consumption by drivers and passengers, were defined as the presence of any burning tobacco product in the hand or mouth of the driver or a passenger. From these variables, two new variables were created: total tobacco consumption (driver and/or passenger) and SHS exposure, that is, if an occupant (driver or passenger) was exposed to SHS. The district variable was categorised into three groups according to the socioeconomic status of the district in question. $^{16}$

We conducted a pilot study ${ }^{17}$ before the fieldwork to evaluate the feasibility of the observations and standardise the data collection sheet, as well as to analyse the degree of agreement between two observers in obtaining information. This pilot study demonstrated the feasibility of the direct observation method and perfect interobserver concordance for monitoring the consumption of tobacco and number of passengers under 14 years of age (simple inter-observer agreement of $100 \%$ and $\kappa$ coefficient $=1.0)$. However, lower inter-observer agreement was found regarding the driver's age (simple interobserver agreement of $94.3 \%$ and $\kappa$ coefficient $=0.865) .{ }^{17}$

\section{Statistical analysis}

We carried out a descriptive analysis of tobacco consumption and SHS exposure stratified by driver, passengers and vehicle variables, and by context. We calculated the prevalence of smoking and SHS exposure and their $95 \%$ CIs. ${ }^{18}$ We performed a $\chi^{2}$ test to compare the prevalence rates. We fitted a logistic regression model to obtain the adjusted OR and 95\% CI of smoking in cars by drivers. All analyses were performed using the statistical package SPSS V.15.

As personal data or biological samples were not used, approval was not required by the Ethics Committee of Bellvitge University Hospital.

\section{RESULTS}

We observed 2442 vehicles, of which $71.1 \%$ were private cars, $19.7 \%$ commercial vehicles and $9.2 \%$ taxis. More than half of the observations $(53.9 \%)$ were conducted on public roads with more than two lanes. The majority $(77.8 \%)$ of drivers were men and the most common age range was $36-64$ years $(69.6 \%)$. There were no passengers in $62.6 \%$ of the vehicles observed. There was 
a passenger under 14 years of age in $29.7 \%$ of the vehicles with passengers $(11.1 \%$ of all vehicles). All windows were closed in $53.4 \%$ of vehicles observed.

Table 1 shows the prevalence of smoking and total SHS exposure of the driver and/or passenger according to type of vehicle. The prevalence of tobacco consumption in vehicles (private, commercial and taxis) was 5.5\% (95\% CI $4.6 \%$ to $6.4 \%)$. The prevalence of tobacco consumption was higher in commercial vehicles $(9.8 \%$, $95 \%$ CI $7.1 \%$ to $12.5 \%)$. The prevalence of tobacco consumption among drivers was $4.7 \%$ (95\% CI $3.9 \%$ to $5.5 \%$ ) and $2.4 \%$ (95\% CI $1.4 \%$ to $3.4 \%$ ) among passengers; this difference was maintained according to vehicle type (table 1 ).

The overall prevalence of SHS exposure was 5.2\% (95\% CI $3.8 \%$ to $6.6 \%$ ). Commercial vehicle occupants were the most exposed to SHS $(12.7 \%, 95 \%$ CI $7.1 \%$ to $18.3 \%$ ), while in taxis there was no observed tobacco consumption or occupant exposure to SHS. Passengers were slightly more likely to be exposed to SHS than drivers $(3.0 \%$ vs $2.2 \% ; \mathrm{p}=0.283)$. This difference was threefold higher in commercial vehicles $(9.7 \%$ vs $3.0 \%$; $\mathrm{p}=0.024)$. The prevalence of passengers under 14 years old exposed to SHS in vehicles was $2.2 \%$ (95\% CI $0.5 \%$ to $3.9 \%$ ) (table 1 ).

Table 2 shows the prevalence of driver tobacco consumption according to vehicle type, driver and vehicle variables, and context. The prevalence of smoking in drivers was almost twofold higher in men than in women $(5.2 \%$ vs $2.9 \% ; \mathrm{p}=0.031)$. There was a statistically significant downward trend in the consumption of tobacco according to the age of the driver, although this trend was not statistically significant in commercial vehicles or taxis. Although consumption of tobacco by drivers was higher in districts with more socioeconomic deprivation $(5.2 \%, 95 \%$ CI $3.8 \%$ to $6.6 \%)$, this difference was not statistically significant. The overall prevalence of tobacco consumption was higher in the morning than in the afternoon $(5.3 \%$ vs $3.8 \% ; \mathrm{p}=0.097)$, especially in commercial vehicles
( $11.6 \%$ vs $4.1 \% ; \mathrm{p}=0.006)$. The prevalence of tobacco consumption among drivers was greater on cloudy than sunny days, regardless of vehicle type (table 2).

In bivariate logistic regression models, we confirmed a stronger association with driver tobacco consumption when the driver was a man (OR $1.79,95 \%$ CI 1.05 to 3.07 ), was $18-34$ years old (OR 9.61, 95\% CI 1.31 to 70.53 ), was driving a commercial vehicle (OR 2.48, 95\% CI 1.66 to 3.69) and had the window open (OR 10.50, 95\% CI 5.86 to 18.82 ) (table 3 ). After adjusting a saturated model with all potential confounders, this association was statistically significant only for the driver's window being open (OR 11.05, 95\% CI 6.08 to 20.09), mornings (OR $1.83,95 \%$ CI 1.20 to 2.79 ) and cloudy weather (OR $1.69,95 \%$ CI 1.11 to 2.57 ) (table 3).

\section{DISCUSSION}

This is the first study in Spain to estimate the prevalence of tobacco consumption and SHS exposure in vehicles through direct observation and shows that both are high in vehicles in Barcelona, especially commercial vehicles.

The prevalence of tobacco consumption in vehicles observed in our study is similar to that demonstrated in studies in Italy ${ }^{12}$ and New Zealand, ${ }^{13}$ where vehicles were also directly observed. However, SHS exposure in vehicles in our study (5.2\%) is much lower than that seen in the New Zealand study (23.7\%). This could be related to social and other variations such as the different population sizes between the areas observed in Wellington in New Zealand $(<410000$ inhabitants $)$ and in Barcelona in Spain (about 1.6 millions inhabitants) and also the different years in which the studies were carried out.

The prevalence rates obtained in studies using questionnaires ${ }^{1419}$ are considerably higher than those estimated in studies using direct observations as in the present study. One reason could be the inability of an observational study to monitor the entire car journey, during which the driver can smoke at any time or smoke more than one cigarette, although the driver's consumption of tobacco during the entire journey can

Table 1 Prevalence (\%) and 95\% confidence interval $(\mathrm{Cl})$ of tobacco consumption and secondhand smoke (SHS) exposure in vehicles in the city of Barcelona, Spain (2011)

\begin{tabular}{|c|c|c|c|c|c|c|c|c|}
\hline & \multicolumn{2}{|l|}{ Total } & \multicolumn{2}{|l|}{ Private } & \multicolumn{2}{|c|}{ Commercial } & \multicolumn{2}{|l|}{ Taxi } \\
\hline & n (\%) & (95\% Cl) & n (\%) & (95\% Cl) & n (\%) & $(95 \% \mathrm{Cl})$ & n (\%) & $(95 \% \mathrm{Cl})$ \\
\hline \multicolumn{9}{|c|}{ Tobacco consumption } \\
\hline $\begin{array}{l}\text { Driver and/or } \\
\text { passenger }\end{array}$ & $2442(5.5)$ & (4.6 to 6.4$)$ & $1736(4.7)$ & (3.7 to 5.7 ) & $482(9.8)$ & (7.1 to 12.5$)$ & $224(2.2)$ & (0.3 to 4.1$)$ \\
\hline Driver & $2442(4.7)$ & (3.9 to 5.5 ) & $1736(3.8)$ & (2.9 to 4.7 ) & $482(8.9)$ & $(6.4$ to 11.4$)$ & $224(2.2)$ & (0.3 to 4.1$)$ \\
\hline Passenger & $913(2.4)$ & (1.4 to 3.4$)$ & $685(2.6)$ & (1.4 to 3.8$)$ & $134(3.0)$ & $(0.1$ to 5.9$)$ & $94(0.0)$ & (0.0 to 3.9$)$ \\
\hline \multicolumn{9}{|l|}{ SHS exposure } \\
\hline Any occupant & $913(5.2)$ & (3.8 to 6.6 ) & $685(4.3)$ & (2.8 to 5.8$)$ & $134(12.7)$ & (7.1 to 18.3 ) & $94(0.0)$ & (0.0 to 3.9$)$ \\
\hline Driver & 913 (2.2) & (1.2 to 3.2$)$ & $685(2.3)$ & (1.2 to 3.4$)$ & $134(3.0)$ & $(0.1$ to 5.9$)$ & $94(0.0)$ & (0.0 to 3.9 ) \\
\hline Passenger & $913(3.0)$ & (1.9 to 4.1$)$ & $685(2.0)$ & (1.0 to 3.0$)$ & $134(9.7)$ & (4.7 to 14.7 ) & $94(0.0)$ & (0.0 to 3.9 ) \\
\hline $\begin{array}{l}\text { Passenger } \\
<14 \text { years old }\end{array}$ & $271(2.2)$ & (0.5 to 3.9$)$ & $253(2.0)$ & (0.3 to 3.7 ) & 12 (8.3) & (1.5 to 35.4$)$ & $6(0.0)$ & (0.0 to 39.0$)$ \\
\hline
\end{tabular}




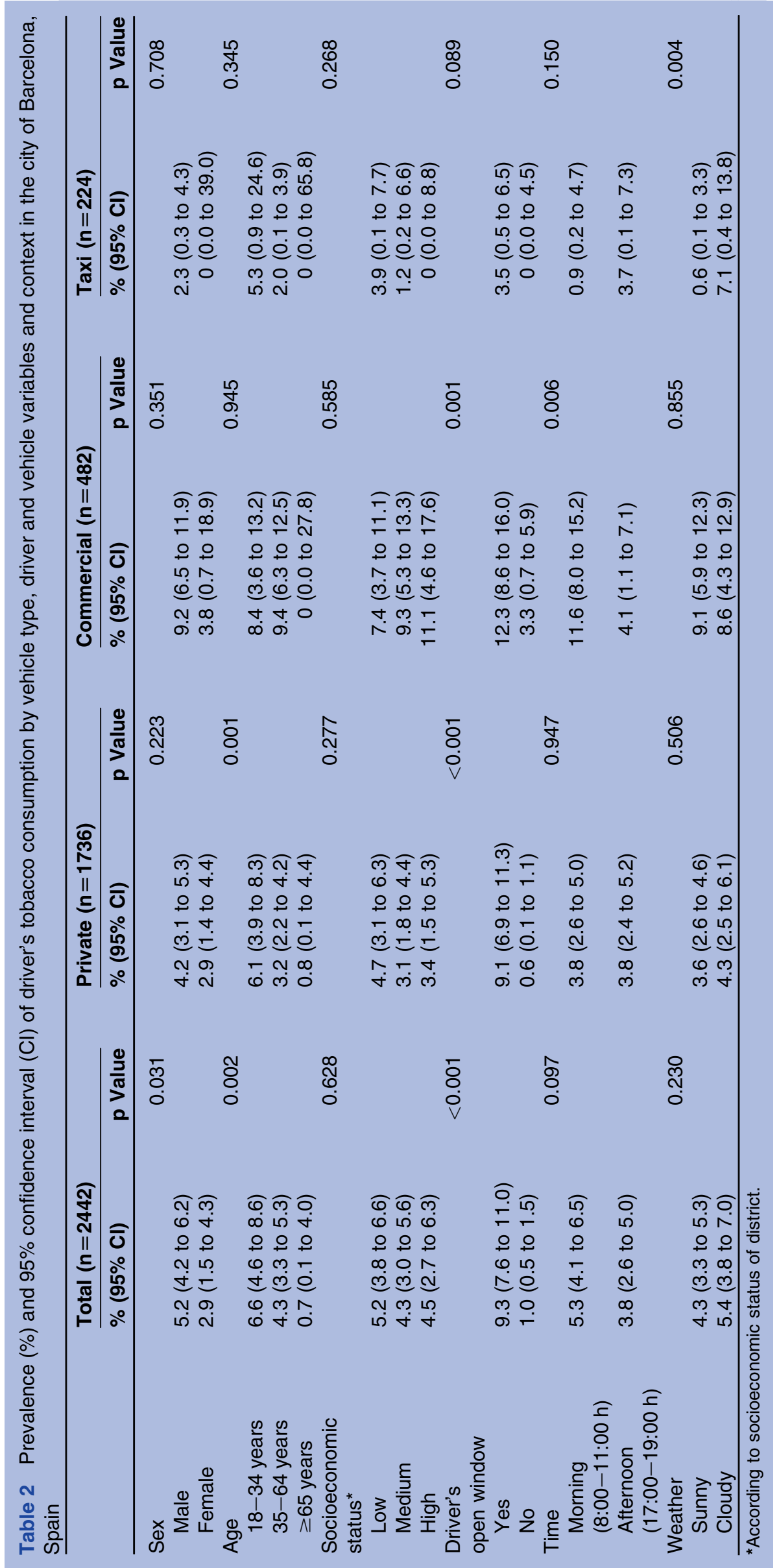


Table 3 Crude and adjusted odds ratio (OR) and 95\% confidence interval (CI) of smoking in cars by drivers

\begin{tabular}{|c|c|c|c|c|}
\hline & cOR $(95 \% \mathrm{Cl})$ & p Value & aOR (95\% Cl) & p Value \\
\hline \multicolumn{5}{|l|}{ Sex } \\
\hline Male & 1.79 (1.05 to 3.07$)$ & 0.033 & 1.46 (0.83 to 2.59$)$ & 0.193 \\
\hline Female & 1 & & 1 & \\
\hline \multicolumn{5}{|l|}{ Age } \\
\hline 18-34 years old & 9.61 (1.31 to 70.53$)$ & 0.026 & 6.85 (0.92 to 51.18$)$ & 0.061 \\
\hline $35-64$ years old & $6.11(0.84$ to 44.30$)$ & 0.073 & $5.12(0.69$ to 37.81$)$ & 0.109 \\
\hline$\geq 65$ years old & 1 & & 1 & \\
\hline \multicolumn{5}{|l|}{ Vehicle type } \\
\hline Private & 1 & & 1 & \\
\hline Commercial & 2.48 (1.66 to 3.69$)$ & $<0.001$ & 1.36 (0.89 to 2.10$)$ & 0.158 \\
\hline Taxi & $0.58(0.23$ to 1.45$)$ & 0.242 & $0.34(0.13$ to 0.86$)$ & 0.023 \\
\hline \multicolumn{5}{|l|}{ Socioeconomic status ${ }^{*}$} \\
\hline Low & 1.15 (0.69 to 1.91$)$ & 0.605 & 1.18 (0.69 to 2.00$)$ & 0.548 \\
\hline Medium & $0.93(0.55$ to 1.58$)$ & 0.801 & 0.98 (0.57 to 1.68$)$ & 0.930 \\
\hline High & 1 & & 1 & \\
\hline \multicolumn{5}{|l|}{ Driver's open window } \\
\hline Yes & 10.50 (5.86 to 18.82$)$ & $<0.001$ & 11.05 (6.08 to 20.09$)$ & $<0.001$ \\
\hline No & 1 & & 1 & \\
\hline \multicolumn{5}{|l|}{ Time } \\
\hline Morning (8:00-11:00 h) & 1.40 (0.94 to 2.08$)$ & 0.099 & $1.83(1.20$ to 2.79$)$ & 0.005 \\
\hline Afternoon (17:00-19:00 h) & 1 & & 1 & \\
\hline \multicolumn{5}{|l|}{ Weather } \\
\hline Sunny & 1 & & 1 & \\
\hline Cloudy & $1.27(0.86$ to 1.89$)$ & 0.231 & 1.69 (1.11 to 2.57$)$ & 0.014 \\
\hline
\end{tabular}

${ }^{*}$ According to socioeconomic status of district.

cOR, crude OR; aOR, adjusted OR derived from a logistic regression model adjusted for driver's sex, age and window, vehicle type, district, time and weather.

be obtained in classical cross-sectional studies using questionnaires. This limitation could lead to an underestimation of prevalence as occurs in studies in bars, which have reported an almost threefold higher number of smokers identified using questionnaires compared with the number found through direct observations. ${ }^{20}$ This aspect should be addressed in future studies.

On the other hand, tobacco consumption in our study was higher when any window in the vehicle was open, as in previous studies. ${ }^{13}$ This may be due to the belief by smokers that the adverse health effects of tobacco consumption in vehicles are minimised when a window is open. ${ }^{21}$ However, although levels of $\mathrm{PM}_{2.5}$ are lower when the vehicle is ventilated, the levels are still unhealthy. ${ }^{6} 91022$

The prevalence of SHS exposure in children was high compared to that observed in the Italian study $(0.9 \%) .{ }^{12}$ This difference could be attributed to the fact that in our study there were schools on half of the public roads selected. This fact should be taken into account since children are inevitably more vulnerable to the effects of SHS exposure. ${ }^{23}$ Indeed, a study conducted in Ireland ${ }^{24}$ found an increased likelihood of developing respiratory and allergic symptoms in children aged 13-14 years old exposed to SHS in vehicles, with wheezing as the most obvious symptom. Therefore, it is clear public health policies in Spain need to focus on reducing tobacco consumption in private cars if children are present. Moreover, a study conducted through telephone surveys in four countries (Australia, Canada, UK and USA) concluded that the majority of smokers (more than $60 \%$ ) would ban smoking in vehicles if children are present, ${ }^{25}$ with higher approval by smokers with less tobacco dependence and with young children $(<5$ years old) versus those without children. This support for restricting smoking in vehicles is also found in studies among adolescents. ${ }^{26} 27$

The observed prevalence of tobacco consumption in commercial vehicles and taxis is especially high considering that under Law $42 / 2010^{28}$ smoking in commercial vehicles and taxis in Spain is banned as they are places of work and public places. Furthermore, since our study found a very high prevalence of tobacco consumption and SHS exposure in commercial vehicles, as seen in Italy, ${ }^{12}$ the current legislation should be more strictly enforced.

On the other hand, tobacco consumption in taxis was never observed in the presence of passengers. Although the passengers of taxis were not directly exposed to SHS, recent studies ${ }^{29} 30$ have highlighted the possible effects of exposure to SHS particles deposited on vehicle seats, as dust or in the air. The involuntary inhalation, ingestion or skin absorption of particles is known as thirdhand smoke exposure. ${ }^{29}$ While there is still insufficient evidence to assess the health hazards from thirdhand smoke, further studies should investigate the potential for exposure to thirdhand smoke and its health effects. 
Tobacco consumption while driving is also a distraction that increases the risk of traffic accidents. ${ }^{31-33}$ It is estimated that drivers who smoke are 1.5 times more likely to have an accident than non-smoking drivers. ${ }^{34}$ Distraction caused by smoking is associated with, among others, decreased dexterity controlling the steering wheel and reduced attention to the road (when the cigarette is being lit or put out and as a result of eye irritation caused by the carbon monoxide present in SHS), in addition to the lower perception of risk that smokers have at the wheel versus non-smokers. ${ }^{34}$ Indeed, a survey conducted by the Spanish National Road Safety Observatory of the General Directorate of Traffic ${ }^{35}$ in 2005 revealed that $83.8 \%$ of interviewed drivers thought that tobacco consumption was a source of distraction while driving. In addition, $76.8 \%$ thought smoking was a fairly or very dangerous behaviour while driving. Given the evidence of the health hazards of smoking while driving and the broad general perception of risk by the population, smoking should be treated the same way as other distractions recognised by Spanish law, such as the use of mobile phones or other manually operated devices, for instance GPS systems. ${ }^{36}$

The main limitation of this study derives from the inherent observer bias, especially regarding variables such as age, as people can look younger or older than they actually are. However, the pilot study ${ }^{17}$ carried out by two independent observers showed almost perfect agreement in observations. We cannot disregard selection bias, since the choice of public roads with a higher density of schools could have resulted in the number of children present in vehicles being over-represented. Other potential limitations of the study are that fieldwork was conducted only in spring and at a particular time of day. However, the Spanish National Health Interview Surveys conducted in several waves during a single year have not shown seasonality in tobacco consumption (prevalence rates by waves for several years are available at http://www.ine.es). Moreover, similar prevalence rates of smoking in vehicles have been reported in autumn, ${ }^{12}$ which also suggests no seasonal differences. Finally, we do not know whether the timewindow used for sampling in our study is representative of the entire $24 \mathrm{~h}$ in a day. While there are fewer vehicles during the night, we do not know if those driving during our sampling time smoke less or more than drivers during the rest of the day or night.

We have used logistic regression as a measure of association in a cross-sectional study. However, the OR only overestimates the prevalence ratio when it is above $20 \%,{ }^{37}$ which is not the case for our data. Also noteworthy is the difficulty of obtaining a truly random and representative sample of vehicles in circulation in a city. Our sampling approach, designed to be representative of all 10 districts of Barcelona, was designed to minimise this limitation. A strength of an observational study like this compared with studies based on the use of questionnaires is the lack of information bias inherent in self-reported data.
In conclusion, this study provides an estimation of smoking in some types of vehicles and highlights the need for public health measures aimed at reducing tobacco consumption in private cars, especially in the presence of children, as well as the enforcement of measures to control smoking in commercial vehicles and taxis.

Acknowledgements We acknowledge the collaboration of Ángel López Rodríguez for providing 'la Araña de Tráfico' of the city of Barcelona.

Funding This work was funded by the Instituto de Salud Carlos III, Government of Spain (RTICC RD06/0020/0089) and the Ministry of Universities and Research, Government of Catalonia (grant 2009SGR192).

\section{Competing interests None.}

Contributors All authors contributed to the design of the study. AC collected the data, prepared the database and analyzed the data. All authors revised the results and contributed to the interpretation of results. AC drafted the manuscript, which was critically revised by JMMS and EF. All authors approved the final version.

Provenance and peer review Not commissioned; externally peer reviewed.

Data sharing statement No additional data available.

\section{REFERENCES}

1. US Environmental Protection Agency. Respiratory Health Effects of Passive Smoking: Lung Cancer and Other Disorders. Washington, DC: Environmental Protection Agency, 1992:6-90.

2. International Agency for Research on Cancer. Monographs on the Evaluation of Carcinogenic Risks to Humans (Vol 83). Tobacco Smoke and Involuntary Smoking. Lyon: International Agency for Reseach on Cancer, 2002.

3. Öberg M, Jaakkola MS, Woodward A, et al. Worldwide burden of disease from exposure to secondhand smoke: a retrospective analysis of data from 192 countries. Lancet 2011;377:139-46.

4. López MJ, Pérez-Ríos M, Schiaffino A, et al. Mortality attributable to passive smoking in Spain, 2002. Tob Control 2007;16:373-7.

5. Dept. of Health and Human Services, Centers for Disease Control and Prevention, National Center for Chronic Disease Prevention and Health Promotion Office on Smoking and Health. The Health Consequences of Smoking: a report of the Surgeon General. Washington, DC: Surgeon General, 2004.

6. Jones MR, Navas-Acién A, Yuan J, et al. Secondhand tobacco smoke concentrations in motor vehicles: a pilot study. Tob Control 2009;18:399-404

7. Vardavas $\mathrm{Cl}$, Linardakis $\mathrm{M}$, Kafatos $\mathrm{AG}$. Environmental tobacco smoke exposure in motor vehicles: a preliminary study. Tob Control 2006;15:415.

8. Rees VW, Connolly GN. Measuring air quality to protect children from secondhand smoke in cars. Am J Prev Med 2006;31:363-8.

9. Sendzik T, Fong GT, Travers MJ, et al. An experimental investigation of tobacco smoke pollution in cars. Nicotine Tob Res 2009;11:627-34

10. Ott W, Klepeis N, Switzer P. Air change rates of motor vehicles and in-vehicle pollutant concentrations from secondhand smoke. $J$ Expo Sci Environ Epidemiol 2008;18:312-25.

11. US Environmental Protection Agency. National Ambient Air Quality Standards For Particulate Matter; Final Rule (Report Num. 71). Washington, DC: Environmental Protection Agency, 2006.

12. Sbrogiò L, Frison G, Tagliapietra L, et al. [Observed smoking in car: results of a study of the Regional Health Prevention Service of Veneto, Northern Italy] (In Italian). Epidemiol Prev 2010;34:43-7.

13. Martin J, George R, Andrews K, et al. Observed smoking in cars: a method and differences by socioeconomic area. Tob Control 2006;15:409-11.

14. Lushchenkova O, Fernández E, López MJ, et al. [Secondhand smoke exposure in Spanish adult non-smokers following the introduction of an anti-smoking law] (In Spanish). Rev Esp Cardiol 2008;61:687-94.

15. Direcció de Serveis de Mobilitat, Ajuntament de Barcelona. Dades Bàsiques de Mobilitat. 2011. http://w3.bcn.es/XMLServeis/ XMLHomeLinkPl/0,4022,173198596_257817017_1,00.htm (accessed 19 Jun 2011).

16. Domínguez-Berjón MF, Borrell C. [Mortality and socioeconomic deprivation in the census tracts and districts of Barcelona] (In Spanish). Gac Sanit 2005;19:363-9. 
17. Martínez-Sánchez JM, Curto A, Fernández E. [Agreement between two observers in the measurement of tobacco consumption, use of safety belt and cell phones in vehicles] (In Spanish). Gac Sanit. Published Online first: 27 October 2011. doi:10.1016/.gaceta.2011.07.011.

18. Wilson EB. Probable inference, the law of succession, and statistical inference. J Am Stat Assoc 1927;22:209-12.

19. Hitchman SC, Fong GT, Borland R, et al. Predictors of smoking in cars with nonsmokers: findings from the 2007 wave of the International Tobacco Control Four Country Survey. Nicotine Tob Res 2010;12:374-80.

20. Repace JL. Exposure analysis. In: Ott WR, Steinemann AC, Wallace LA, eds. Exposure to Secondhand Smoke. NY: Taylor \& Francis Group, 2007:201-35.

21. Kegler MC, Escoffery C, Butler S. A qualitative study on establishing and enforcing smoking rules in family cars. Nicotine Tob Res 2008;10:493-7.

22. Invernizzi G, Ruprecht AA, Mazza R, et al. [Smoking in car: monitoring pollution of particulate matter, of organic volatile compounds and of carbon monoxide. The effect of opening the driver's window] (In Italian). Epidemiol Prev 2010;34:35-42.

23. Bearer CF. How are children different from adults? Environ Health Perspect 1995;103(Suppl 6):7-12.

24. Kabir Z, Manning PJ, Holohan J, et al. Secondhand smoke exposure in cars and respiratory health effects in children. Eur Respir $J$ 2009;34:629-33.

25. Hitchman SC, Fong GT, Zanna MP, et al. Support and correlates of support for banning smoking in cars with children: findings from the ITC Four Country Survey. Eur J Public Health 2011;21:360-5.

26. Leatherdale ST, Smith P, Ahmed R. Youth exposure to smoking in the home and in cars: how often does it happen and what do youth think about it? Tob Control 2008;17:86-92.

27. Leatherdale ST, Ahmed R. Second-hand smoke exposure in homes and in cars among Canadian youth: current prevalence, beliefs about exposure, and changes between 2004 and 2006. Cancer Causes Control 2009;20:855-65.

28. Boletín Oficial del Estado. Ley $42 / 2010$ por la que se modifica la Ley 28/2005 de medidas sanitarias frente al tabaquismo y reguladora de la venta, el suministro, el consumo y la publicidad de los productos del tabaco. http://www.boe.es/boe/dias/2010/12/31/pdfs/BOE-A2010-20138.pdf (accessed 21 Jun 2011).

29. Matt GE, Quintana PJ, Destaillats $\mathrm{H}$, et al. Thirdhand tobacco smoke: emerging evidence and arguments for a multidisciplinary research agenda. Environ Health Perspect 2011;119:1218-26.

30. Matt GE, Quintana PJ, Hovell MF, et al. Residual tobacco smoke pollution in used cars for sale: air, dust, and surfaces. Nicotine Tob Res 2008;10:1467-75.

31. Sacks JJ, Nelson DE. Smoking and injuries: an overview. Prev Med 1994:23:515-20.

32. Wen CP, Tsai SP, Cheng TY, et al. Excess injury mortality among smokers: a neglected tobacco hazard. Tob Control 2005;14(Suppl 1): i28-32.

33. Buñuel JM, Córdoba $\mathrm{R}$, del Castillo $\mathrm{M}$, et al. Smoking and nonfatal traffic accidents. Atención Primaria 2003;31:349-53.

34. Brison RJ. Risk of automobile accidents in cigarette smokers. Can J Public Health 1990;81:102-6.

35. Soria J. Si conduce, mejor no fume. Tráfico y Seguridad Vial 2005; $172: 38-9$

36. Boletín Oficial del Estado. Ley 17/2005, de 19 de julio, por la que se regula el permiso y la licencia de conducción por puntos y se modifica el texto articulado de la ley sobre tráfico, circulación de vehículos a motor y seguridad vial. http://www.boe.es/boe/dias/2005/07/20/ pdfs/A25781-25793.pdf (accessed 21 Jun 2011).

37. Schiaffino A, Rodríguez M, Pasarín MI, et al. [Odds ratio or prevalence ratio? Their use in cross-sectional studies]. (In Spanish). Gac Sanit 2003;17:70-4. 